\title{
RESSONÂNCIA MAGNÉTICA DO ENVOLVIMENTO CEREBRAL NA HEMIATROFIA FACIAL PROGRESSIVA (DOENÇA DE ROMBERG)
}

\author{
RECONSIDERAÇÃO DE UMA SÍNDROME
}

\author{
K. TERSTEGGE* B. KUNATH**, S. FELBER ${ }^{* \star *}$, J.G. SPECIALI***, \\ M. BECKERT ${ }^{*}$ H. HENKES ${ }^{* \star}$, N. HOSTEN*
}

\begin{abstract}
RESUMO - A hemiatrofia facial progressiva (HFP) é doença esporádica de etiologia não esclarecida, caracterizada por progressiva atrofia e deformação de um dos lados da face. Os relatos e interpretaçóes de comprometimento do sistema nervoso central na HFP, conforme deduzido pela ocorrência de crises epilépticas em alguns pacientes e pela documentação por pneumencefalografia e CT em pequenas séries de pacientes, são contraditórios. Examinamos três pacientes do sexo feminino com HFP, uma com epilepsia, com o objetivo de obter mais informaçōes sobre a patogênese da doença. Métodos: Realizamos exames de ressonância magnética nuclear (RMN) de rotina da cabeça e face. Resultados: Apenas a paciente com epilepsia apresentou achados patológicos no cérebro. Estes eram confinados ao hemisfério homolateral à hemiatrofia facial : dilatação monoventricular, dismorfismo meningo-cortical e alteraçð̄es na substância branca . Conclusōes: As alteraçōes morfológicas verificadas à RMN assim como os achados neurorradiológicos e histopatológicos mostrados em revisāo da literatura indicaram que a hemiatrofia homolateral é achado típico para um subgrupo de pacientes com HFP, mas năo indica um modelo de simples processo atrófico. Reconsideramos a possibilidade de uma meningoencefalite crónica com acometimento vascular como possível causa do ocasional envolvimento cerebral na HFP.
\end{abstract}

PALAVRAS-CHAVE: hemiatrofia facial progressiva, cérebro, ressonância magnética, esclerodermia localizada da face.

Magnetic resonance of brain involvement in progressive facial hemiatrophy (Romberg's disease): reconsidering a syndrome

SUMMARY - Progressive facial hemiatrophy (PFH) is a sporadic disease of unclear etiology, characterized by shrinking and deformation of one side of the face. Reports and interpretations of CNS involvement in PFH, as deduced from the occurrence of seizures in some patients and documented by pneumoencephalography and $\mathrm{CT}$ findings in small series of patients, are contradictory. We examined three female patients with PFH, one with partial epilepsy, with the view to gaining further insight into the pathogenesis of the disease. Methods: Routine MR examinations of the head and face were performed. Results: Only the patient with epilepsy showed pathological findings, confined to the cerebral hemisphere homolateral to the facial hemiatrophy, and including monoventricular enlargement, meningo-cortical dysmorphia and white matter changes. Conclusions: The MR morphology, and corresponding neuroradiological and histopathological findings disclosed by a review of the

*Departament of Radiology, Universitätsklinikum Rudolf Virchow, Freie Universität Berlin (Spandauer Damm 130, 1000 Berlim 19, Deutschland); **Klinik und Poliklinik für Neurologie, Medizinische Akademie "Carl Gustav Carus" (Fetscherstrasse 74, D-O-8019 Dresden, Deutschland); ***Institut für Neuroradiologie, Universitätskliniken der Universität Homburg (D-W-6650 Homburg/Saar, Deutschland); ****Departamento de Neuropsiquiatria, Hospital das Clínicas, Faculdade de Medicina de Ribeirão Preto, Universidade de São Paulo (14049-900 Ribeirão Preto SP, Brasil). Aceite: 27-julho-1994.

Dr. K. Terstegge - Universitätsklinikum Rudolf Virchow - Augustenburger Platz 1 - 13353 Berlin - Deutschland. Fax (49) (4505) 2078. 
literature, indicate that homolateral hemiatrophy is a typical finding for a subgroup of PFH patients, but do not support the model of a simple or nutritive atrophic process. We reconsider chronic localized meningo-encephalitis with vascular involvement as possible underlying cause of the occasional brain involvement in PFH.

KEY WORDS: progressive facial hemiatrophy, brain, magnetic resonance, localized sclerodermia.

Hemiatrofia facial progressiva (HFP), também conhecida por síndrome de Romberg ou síndrome de Parry-Romberg, é doença esporádica, intrigante, mas não extremamente rara. É caracterizada por progressiva atrofia e deformação de um dos lados da face envolvendo diferentes tecidos ${ }^{2,33,39,40,51}$. O início dos sintomas ocorre principalmente nas duas primeiras décadas ${ }^{38,46}$. Alopécia unilateral circunscrita de vários graus frequentemente precede a desnivelamento inferior da pele. Tais áreas, como já notado desde as primeiras descrições, nunca cruzam a linha mediana e podem dar a impressão de áreas de inervação dos nervos cranianos especialmente o quinto. Em raros casos estas áreas podem estender-se para o tronco e para os membros ipsilaterais. $O$ sintoma principal e a maior causa da perda de substância parece ser a atrofia da gordura subcutânea ${ }^{2.51}$. Frequentemente se acompanha de alterações semelhantes a uma cicatriz na pele $\mathrm{e}$ as vezes por osteoporose circunscrita, que pode levar a deformação óssea. A síndrome dermatológica que se aproxima da HFP é a esclerodermia circunscrita (morfea) "en coup de sabre" da face ${ }^{50}$. Entretanto, investigadores experientes como Möbius ${ }^{30}$, Cassirer ${ }^{7}$, Wartenberg ${ }^{51}$ e Rees $^{36}$ apontam que a diferenciação clínica e laboratorial entre HFP e esclerodemia localizada não é possível ou tenha utilidade. Em décadas anteriores, o tratamento mais frequentemente utilizado era a cirurgia plástica ${ }^{34.36}$. Enquanto a causa ou causas da HFP ainda esperam definição, os modelos patogenéticos têm sido divididos em submodelos competitivos de "trofoneurose" ${ }^{39}$, que atribui a atrofia facial a lesōes ou disfunçōes de vários nervos tróficos ou de centros tróficos superiores ${ }^{2.51}$ Outros modelos independentes, têm proposto uma doença tecidual localizada do tecido subcutâneo e da pele ${ }^{21,22,30}$. Sintomas de acometimento de nervos periféricos da face têm sido frequentemente registrados ${ }^{2,51}$. Episódios meningíticos febris $\mathrm{e}$ enxaquecas assim como sintomas inequívocos de envolvimento do sistema nervoso central (SNC), especialmente epilepsia e hemiparesia, têm sido relatados num pequeno subgrupo, estimado em $15 \%$ dos pacientes com HFP'. Conquanto Archambault ${ }^{2}$ acreditasse que a ocorrência de epilepsia na HFP fosse pura coincidência, Wartenberg ${ }^{51}$ sugeriu que ambas, HFP e epilepsia, pudessem ser consideradas como partes de uma única doença. Seus argumentos foram: (a) a incidência da epilepsia e (b) a frequencia da associação temporal do início da HFP e da epilepsia. Seu ponto mais forte entretanto foi (c) a ocorrência de epilepsia parcial claramente relacionada ao hemisfério ipsilateral à HFP em número significativo de pacientes, dando apoio à evidência de alterações analogamente relacionadas na face e no cérebro. A concepção de Wartenberg do acometimento ipsilateral da face e do cérebro não foi, contudo, sistematicamente investigada e pelo contrário, nas últimas décadas, poucos autores têm descrito alterações neurorradiológicas homo ou contralaterais às alterações da face em séries de pacientes com HFP,11. Ainda que tal acometimento cerebral contralateral não pareça compatível às variantes do modelo de "trofoneurose" ou tampouco da "doença tecidual", por enquanto, novos modelos não surgiram para explicar tais contradiçōes.

A imagem por ressonância magnética nuclear (RMN) é exame que propicia alta resolução do cérebro normal e patológico. Seu uso em pacientes com HFP pode contribuir para melhor compreensão de suas manifestaçōes no SNC e das controvérsias referidas. A fim de interpretar os achados da RMN de nossos pacientes foi também necessário uma completa revisão da literatura.

\section{MATERIAL E MÉTODOS}

A. Pacientes. Examinamos três mulheres com idades entre 27 e 61 anos com diagnóstico da síndrome de Romberg, todas com atrofia esquerda da face. Os dados clínicos dessas pacientes estão apresentados na Tabela 1. O início dos sintomas faciais ocorreu por volta da segunda ou terceira década e a duração da moléstia variou de 34 a 47 anos. Apenas uma paciente (HU) apresentava quadro neurológico, indicando claramente acometimento 


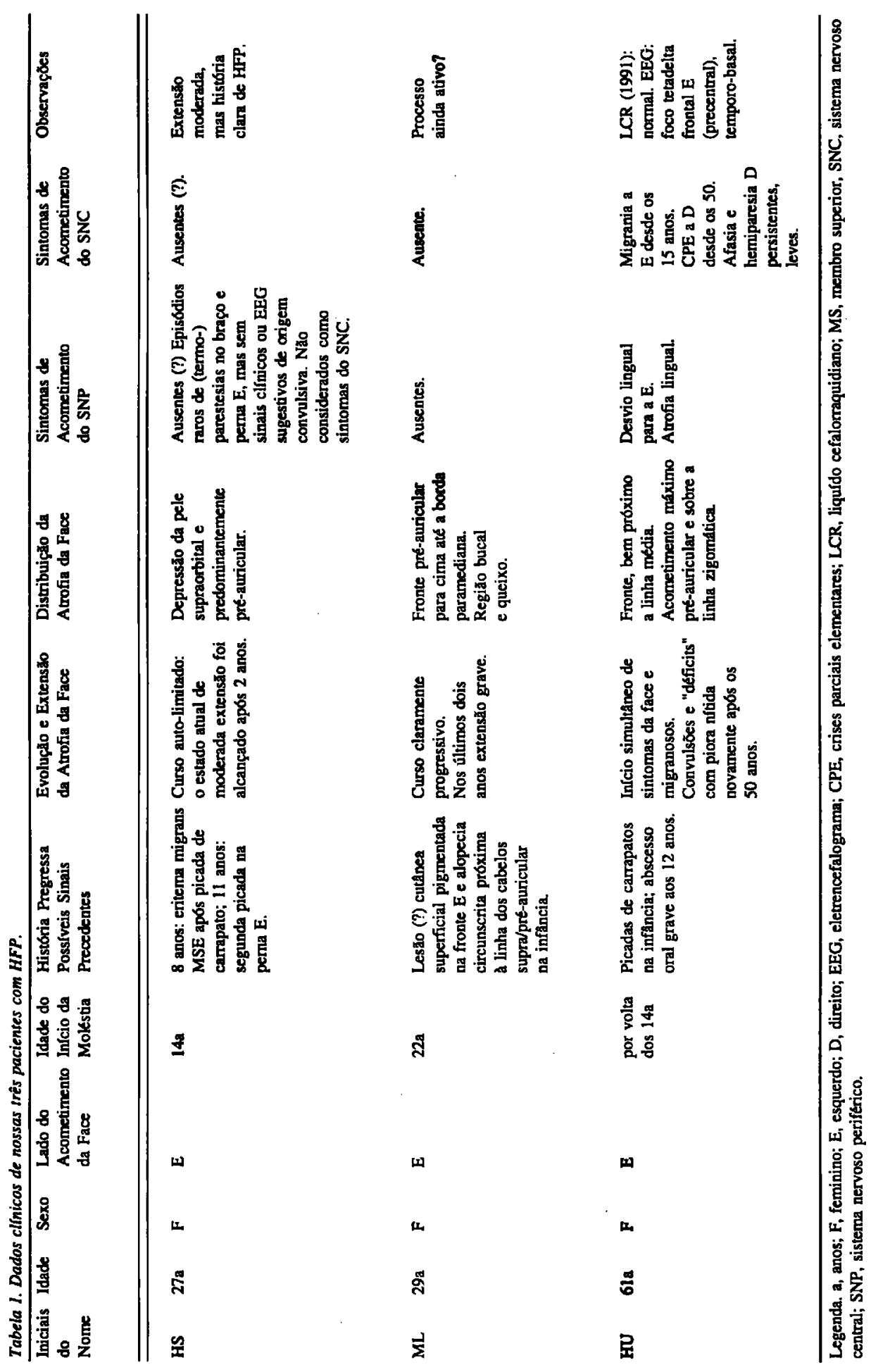


do SNC. Tinha enxaqueca complicada a esquerda, com hemiparesia direita, hemianopsia e afasia desde os 15 anos de idade. Apresentou evolução nitidamente progressiva com o aparecimento de crises epilepticas parciais refratárias ao tratamento, após a idade de 50 anos. Nesta paciente o exame mostrou afasia, hemiparesia e "deficits" cognitivos pouco pronunciados. A paciente HS contava raros episódios de parestesias na regi 30 acometida da face, que ocasionalmente se estendiam para os membros homolaterais. Estas parestesias năo foram consideradas como claramente indicativas de acometimento do SNC.

B. RMN. Todas as pacientes foram submetidas a estudo de rotina de RMN do cranio e da face. Relataremos apenas os achados intracranianos. Os exames foram feitos num tomógrafo de campo médio (Siemens Magneton) de $0.5 \mathrm{~T}$ (pacientes HU e HS) e num tomógrafo de campo alto (Siemens Magneton SP) de $1.5 \mathrm{~T}$ (paciente ML). Todos os exames inclúam administração de contraste (dimeglubina gadopentato Gd-DTPA, Magnevist, Schering). As imagens foram analisadas cooperativamente por dois de nós (K.T. e H.H.) e os achados patológicos săo apresentados em detalhe neste relato.

C. Reviş̄o da literatura. A partir de dados de uma revisão abrangente da literatura, tentamos fazer uma classificaçăo sistemática dos achados radiológicos.

Foram aceitos os achados pneumencefalograficos (PEG) e de tomografia computadorizada (CT) de pacientes com HFP não congênita e nitidamente progressiva, independentemente dos sintomas neurol6gicos relatados. Não procuramos distinguir entre HFP e esclerodermia localizada (EL) "en coup de sabre" nesta revisão, como alguns autores fizeram" ${ }^{11}$. No entanto, apenas um paciente (Tabela 2: 38) que tinha somente o diagnóstico de EL foi incluŕdo, enquanto alguns outros tinham ambos os diagnósticos.

Radiografias de cránio foram aceitas para a classificaçåa de dois pacientes com lesరes calcificadas intracranianas, ainda que resultados de craniogramas nāo tenham sido sistematicamente revisados. Um paciente (Tabela 2: 4) apareceu em dois relatos independentes. Os sintomas clínicos descritos de todos os pacientes (39 pacientes em 40 relatos) foram revistos para o conceito de "sintomas altamente indicativos" de acometimento do SNC (a seguir chamados "sintomas centrais"). Aceitamos epilepsia, hemiparesia, hemianopsia e incoordenaçāo cerebelar como altamente indicativos de acometimento do SNC. Migrânia acompanhada por hemiparesia paroxística e hemianopsia também foi aceita para um paciente. As epilepsias foram classificadas baseando-se nos relatos como crises generalizadas (com ou sem evidência de generalização secundária), crises parciais elementares e crises parciais complexas. A lateralização do possível acometimento cerebral deduziu-se a partir dos sintomas (Tabela 2). Somente nos pacientes em que as crises não puderam ser atribuidas a um lado, os dados eletrencefalográficos (EEG) foram considerados para auxiliar a estabelecer a lateralizaçăo. Não suspeitamos de acometimento cerebral ou lateralizaçăo em pacientes sem "sintomas centrais".

Os achados radiológicos foram analisados com relação a sinais de hemiatrofia cerebral ou cerebelar (aumento externo do espaço subaracnóideo ou ventricular), lesăo parenquimatosa e, separadamente, achados de calcificação intracraniana. Tal conduta pareceu ser adequada para transportar os achados descritivos de diferentes técnicas para seus correlatos correspondentes. Năo se concluiu "atrofia cerebral" através de craniogramas nem "lesões parenquimatosas", do PEG. Pela comparação do lado do acometimento facial com os achados neurorradiologicos lateralizados, os pacientes foram classificados em uma das três categorias seguintes: (1) pacientes com acometimento homolateral neurorradiologicamente comprovado $(\mathrm{H})$, subclassificados conforme um ou mais aspectos em hemiatrofia cerebral (a), calcificaçăo (c) ou realce (e); (2) pacientes com achados normais $(N)$ e pacientes com achados cerebrais contralaterais $(O)$. As ilustraçðes disponíveis dos relatos foram criticamente revisadas, sendo indicadas as avaliaçð̃es discordantes.

Também, todas as descriçōes de biópsias ou necrópsias dos pacientes com HFP foram revistas independentemente de suas idades. Foram excluídos um relato de autópsia de um paciente com evolução atípica ${ }^{14}$ de HFP, um paciente com relato de esclerose múltipla intercorrente ${ }^{15}$ e um com história de trauma crânioencefálico grave ${ }^{49}$. Os três relatos de autópsia restantes e dois de biópsia cerebral foram revistos e resumidos.

\section{RESULTADOS}

A. Estudos com RMN. Todas as nossas pacientes apresentaram achados patológicos extra cranianos; entretanto, este não é o objetivo deste estudo.

Os achados cerebrais de duas pacientes foram normais. As pacientes HS e ML não apresentaram "déficits" neurológicos. A RMN da terceira paciente (HU), que tinha enxaqueca desde a idade de 15 anos, mostrou alteraçס̄es complexas no hemisfério homolateral as alteraçóes da face (Fig 1). 


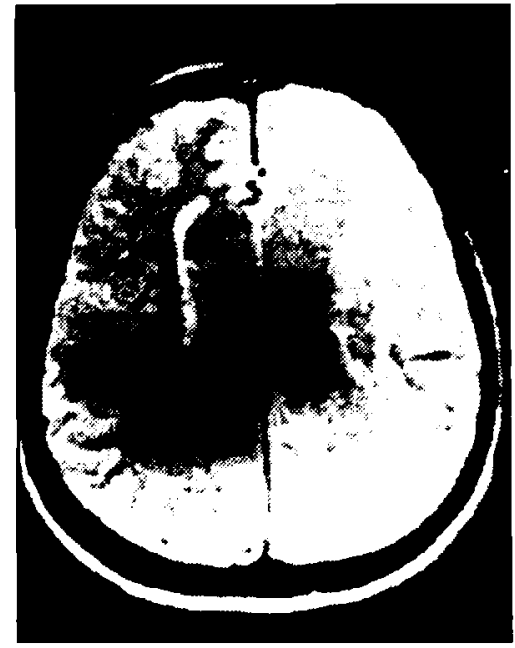

Fig JA. Paciente HU. RMN(T2) mostra ampla área de hiperintensidade da substância branca nos lobos frontal e parietal, anterior e superiormente ao ventriculo lateral esquendo. A área engloba a maior parte do territbrio da artéria cerebral anterior mas nao se confina a ela.
As imagens em T2 da paciente HU revelaram hiperintensidade raiada da substância branca no hemisfério cerebral homolateral que incluia o território vascular da artéria cerebral anterior, porém nāo totalmente confinada a ele (Fig 1A). Nesta área, principalmente nas convexidades frontal esquerda e parietal e nas superfícies interhemisféricas desses lobos, os sulcos extracerebrais eram mal definidos e apareciam como região isointensa ao cérebro, livres de líquido cefalorraquidiano (LCR) nas imagens T-1 (Fig 1B-C). O ventrículo lateral esquerdo estava ampliado, especialmente no corno anterior e no corpo, enquanto o teto mostrava contornos algo ondulados (Fig 1C-D-E). $O$ aumento do ventrículo pareceu-nos muito desproporcional à redução dos sulcos. Dismorfias girais ou meningocorticais davam a impressão de adesōes meníngeas (Fig 1CD). Na maior parte das zonas meningo-corticais acometidas, as meninges não podiam ser claramente diferenciadas, mesmo após a aplicação de Gd-DTPA, porém as paredes da artéria cerebral anterior direita e um ramo da artéria cerebral média esquerda mostraram-se levemente aumentadas, em placas em alguns cortes (Fig 1 E-F).

B. Revisão dos achados neurorradiol6gicos relatados na literatura. Esta revisão não pretende ser completa, particularmente devido ao fato de que os achados estāo descritos em diferentes línguas e por profissionais de várias áreas.

Revisamos 40 relatos ( 39 pacientes) de HFP, incluindo 24 com "sintomas centrais". Somente 15 deles estavam incluídos em investigaçōes de séries ${ }^{3,11,35,37}$, enquanto os demais foram descritos em relatos de casos. Apenas um estudo lidou primariamente com os achados neurorradiológicos ${ }^{3}$. A maioria dos achados neurorradiológicos foi apresentada sucintamente.

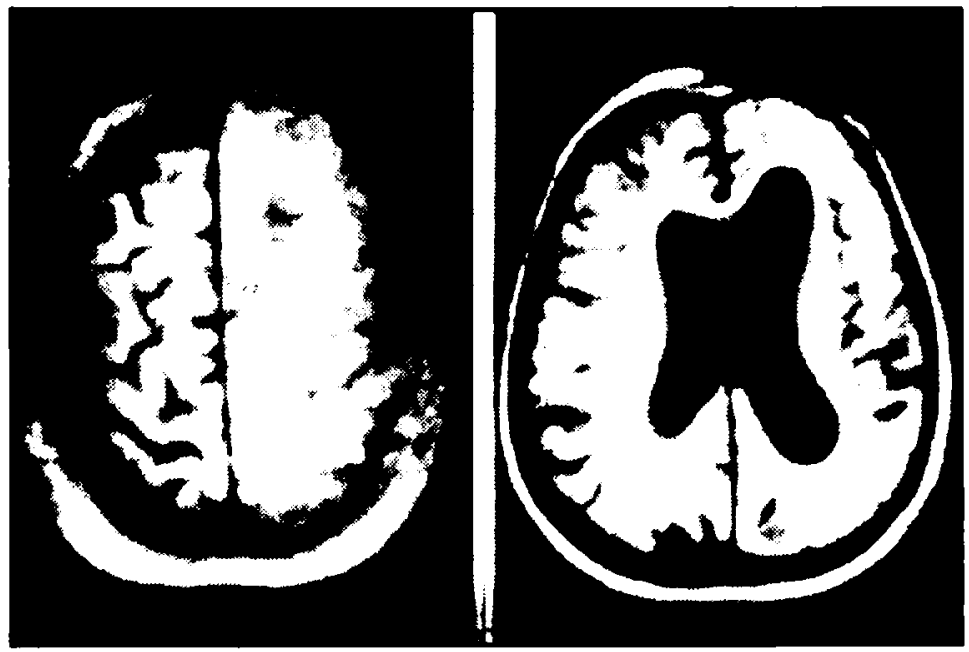

Fig IB,C. Paciente HU. RMN(TI) mostra anormalidades grosseiras da supe ficie cerebral: amplas áreas com desaparecimento dos sulcos na convexidade e superficie inter-hemisférica d̀ esquerda (dismorfia córtico-meningea); o ventrículo lateral está alargado, deste lado. 

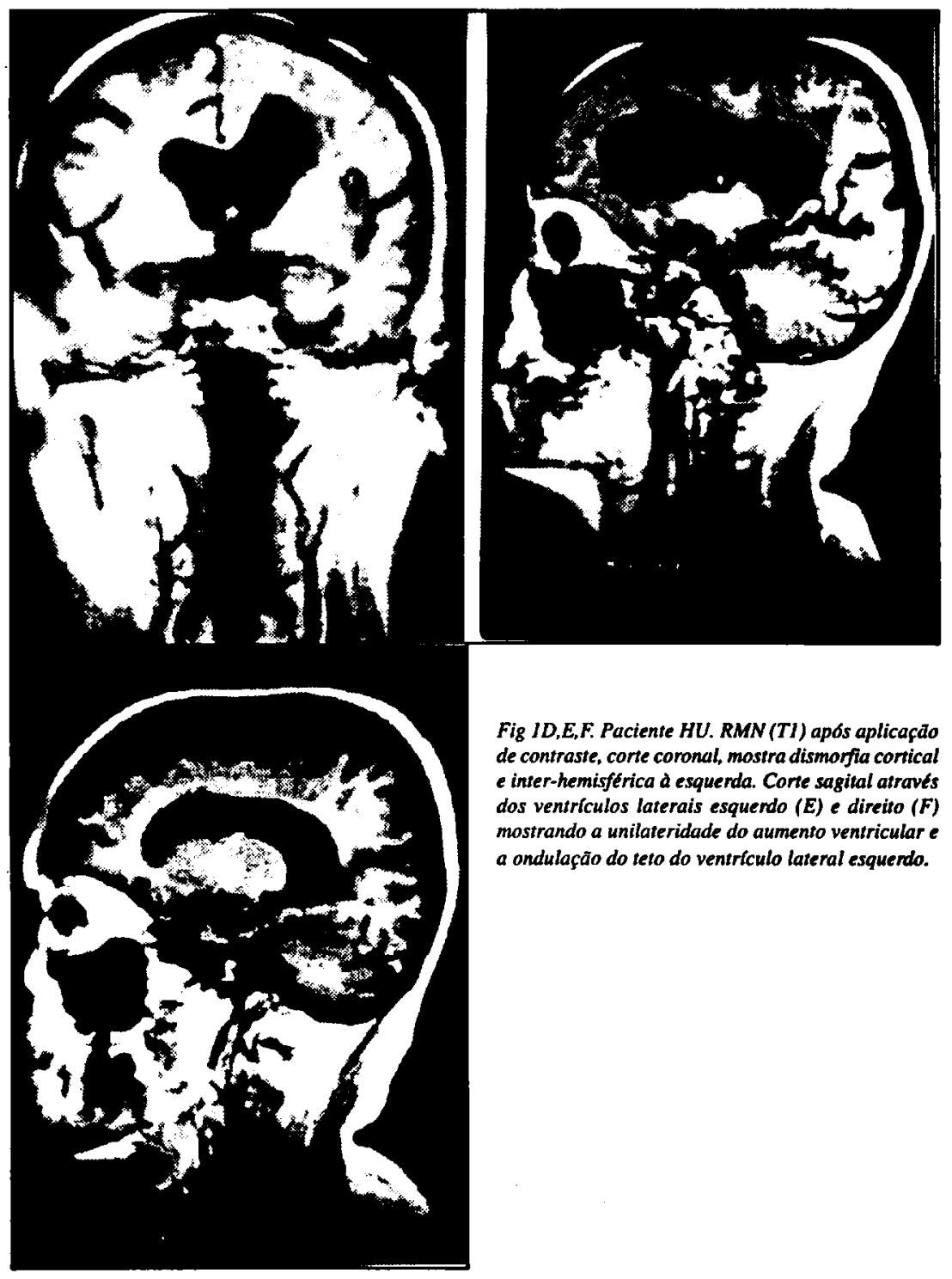

Fig ID,E,F. Paciense HU. RMN(TI) apds aplicafdo de contraste, corte coronal, mostra dismorfia contical $e$ inter-hemisférica de esquenda. Conte sagital atraves dos ventrículos laterais esquerdo $(E)$ e direito $(F)$ mostrando a unilateridade do aumento ventricular $e$ a ondulação do teto do ventriculo lateral esquerdo.

Achados normais foram descritos em 15 pacientes. Dez desses não tinham qualquer dos "sintomas centrais" definidos acima. Quatro dos 5 restantes tinham epilepsia: em 2 ela foi atribuída ao hemisfério homolateral com base em avaliações clínicas, e não se pôde localizar a lesão nos outros 2. $O$ paciente restante, com achados normais mas com "sintomas centrais", apresentava afasia e hemiparesia direita intermitente sugerindo acometimento cerebral contralateral à atrofia facial (Tabela 2:34).

Um total de 18 pacientes apresentava achados patológicos cerebrais do lado da hemiatrofia facial. Desses 18 pacientes, 12 tinham crises parciais (e outras) e 3 tinham somente crises generalizadas (mas com EEG focal em 2 deles) ${ }^{18,21}$. Um menino tinha enxaqueca acompanhada lateralizada e uma menina tinha hemiparesia. Somente 1 desses 18 pacientes com achados neurorradiológicos patológicos homolaterais não tinha "sintomas centrais". Dezesseis desses pacientes mostraram sinais de hemiatrofia cerebral homolateral, principalmente sob a forma de aumento monoventricular [raramente com hemiatrofia cerebelar do mesmo lado (Tabela 2: 19 e 29)]. Três dos 18 pacientes com achados patológicos neurorradiológicos homolaterais tinham calcificações corticais no 


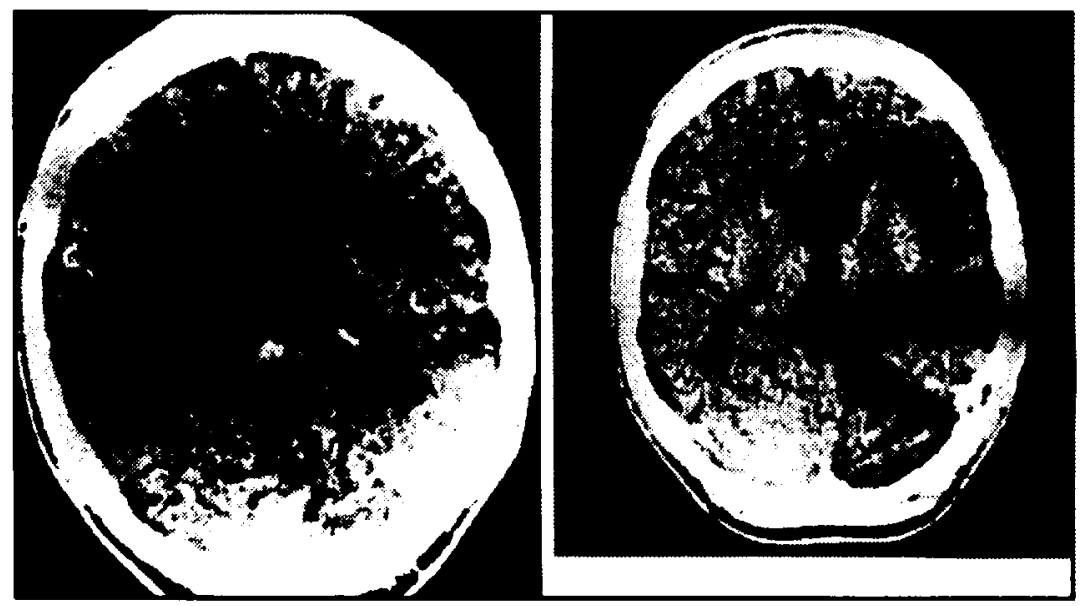

Fig 2 A,B. Paciente DAM. CT mostrando alargamento dos comos frontal e semporal do ventriculo lateral esquerdo, hemiatmofia cerebelar esquenda, hipodensidade do parenquima cerebral esquerdo e perda dos sulcos com dismorfia giral desse mesmo lado.

hemisfério homolateral ao envolvimento da face. Em 1 deles, que tinha apenas radiografias do crânio, este foi o único achado patológico, enquanto os 2 outros tinham também hemiatrofia homolateral. A CT do paciente restante (Tabela 2: 25) com achados patologicos homolaterais mostrou realce difuso cortical ou meníngeo após o contraste. Nos 18 pacientes com achados neurorradiológicos patológicos evidenciando lesão cerebral homolateral, a lateralidade pode ser deduzida a partir dos sintomas neurológicos em 14, somente pelo EEG em 2 e de nenhum modo em 1 paciente com e em 1 outro sem "sintomas centrais".

Hipodensidade parenquimatosa homolateral foi relatada explicitamente em apenas 1 paciente (Tabela 2: 33), mas póde ser retrospectivamente reconhecida, após a revisão critica das CTs, nos pacientes 4 (segundo estudo), 29 e 33 (Tabela 2) e possivelmente outros (veja Fig 2; os dados da revisăo crítica nẫo estão apresentados na Tabela 2). A desproporção entre alargamento ventricular significativo e sulcos pequenos na convexidade estava presente nos pacientes 4 (segundo estudo) e 29. As imagens dos pacientes 25 e 33 foram julgadas retrospectivamente como mostrando dismorfia giral localizada (veja Fig 2).

Achados neurorradiologicos patologicos contralaterais foram descritos em 4 pacientes. Três desses tinham aumento ventricular contralateral. Dois desses 3 năo tinham qualquer "sintoma central" ou qualquer outro sintoma neurologico. O terceiro paciente (Tabela 2: 12) tinha tido o início da epilepsia 3 anos apos o início da atrofia facial, mas esta não pode ser atribuída a qualquer dos hemisférios nem por sinais clinicos nem pelo EEG. A CT do quarto paciente (Tabela 2: 27) mostrou lesão hiperdensa e não realçada pelo contraste na substância branca contralateral pos-central. Esse paciente tampouco tinha sintomas neurológicos.

Dois pacientes năo puderam ser colocados em quaisquer dos presentes grupos [achados normais $(N)$ ou achados neurorradiologicos homolaterais $(\mathrm{H})$ ou contralaterais $(\mathrm{O})$ ] devido a informaç̧̃̃o insuficiente sobre os achados patológicos. A relação entre os achados patológicos homolaterais e contralaterais foi 18 para 4. A mesma relagăo, porem concernente aos "sintomas centrais", $€$ 17:1.

C. Revisåo dos achados de biópsia e autópsia. Os exames histológicos dos fragmentos da face dos pacientes com HFP revelaram neurite ou neurovasculite proliferativa intersticial ${ }^{27}$. A microscopia eletrónica mostrou infiltrados linfocíticos e alteraçð̃es nas membranas basais vasculares e no endotélio ${ }^{34}$. Poucos são os relatos de autópsia cerebral de pacientes com HFP publicados, nenhum deles recente. $O$ paciente de Mendel, que nato referia qualquer "sintoma central" como descrito acima, tinha achados cerebrais normais exceto por discreta atrofia do núcleo rubro e das raízes trigeminais homolaterais à atrofia da face ${ }^{27}$. Fromhold-Treu descreveu os achados de autopsia ${ }^{12}$ de um paciente, que em vida havia sido examinado por Graff ${ }^{13}$. Este paciente (LS) foi tratado (aparentemente de maneira presuntiva) de sífilis terciária. Ele tinha afasia amnéstica, dificuldade inespecffica de marcha e desenvolveu rapidamente demência com concomitante atrofia facial esquerda severa. A autópsia mostrou espessamento acastanhado, com neoformação vascular e equimose, da meninge homolateral. 


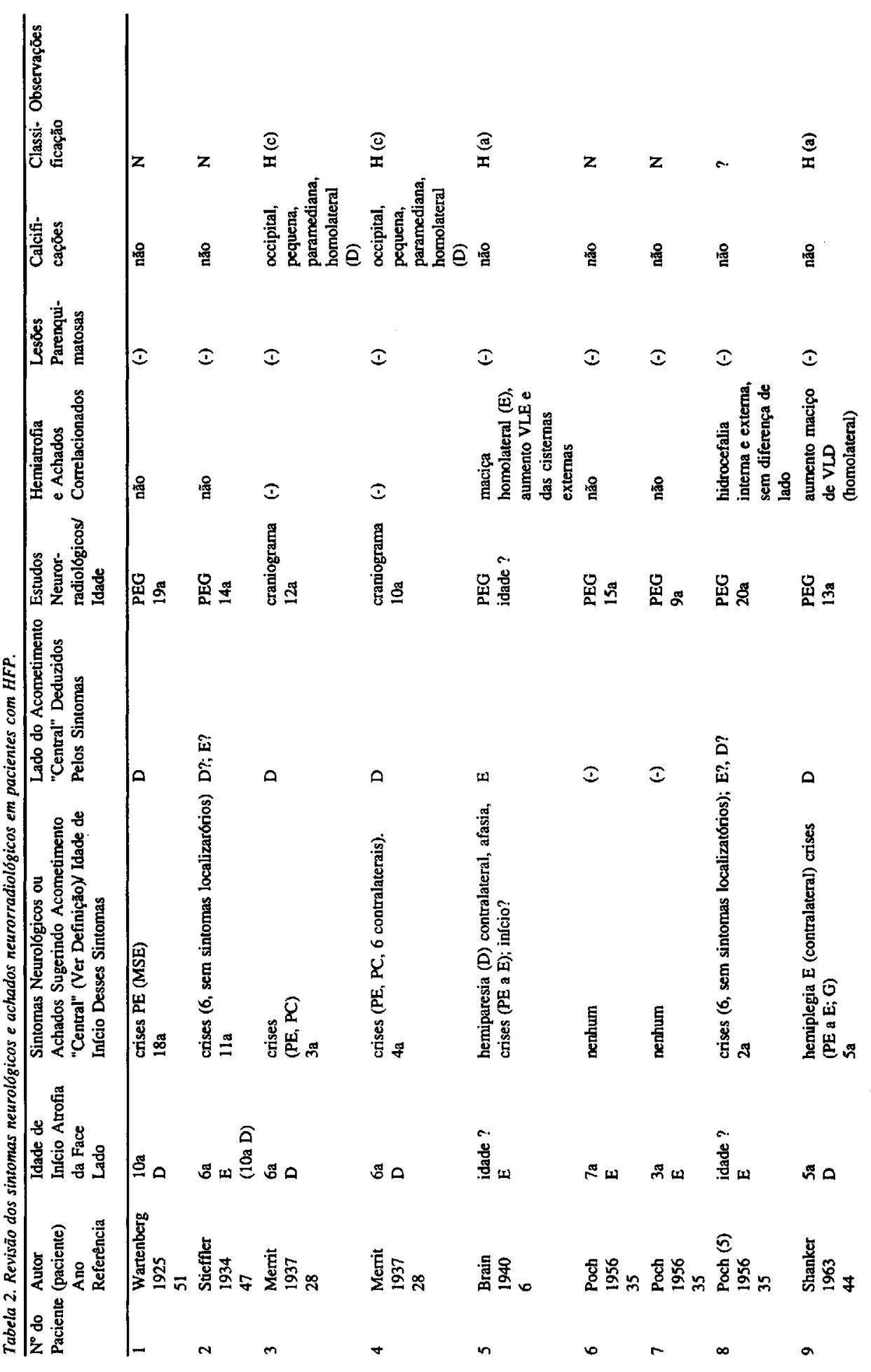




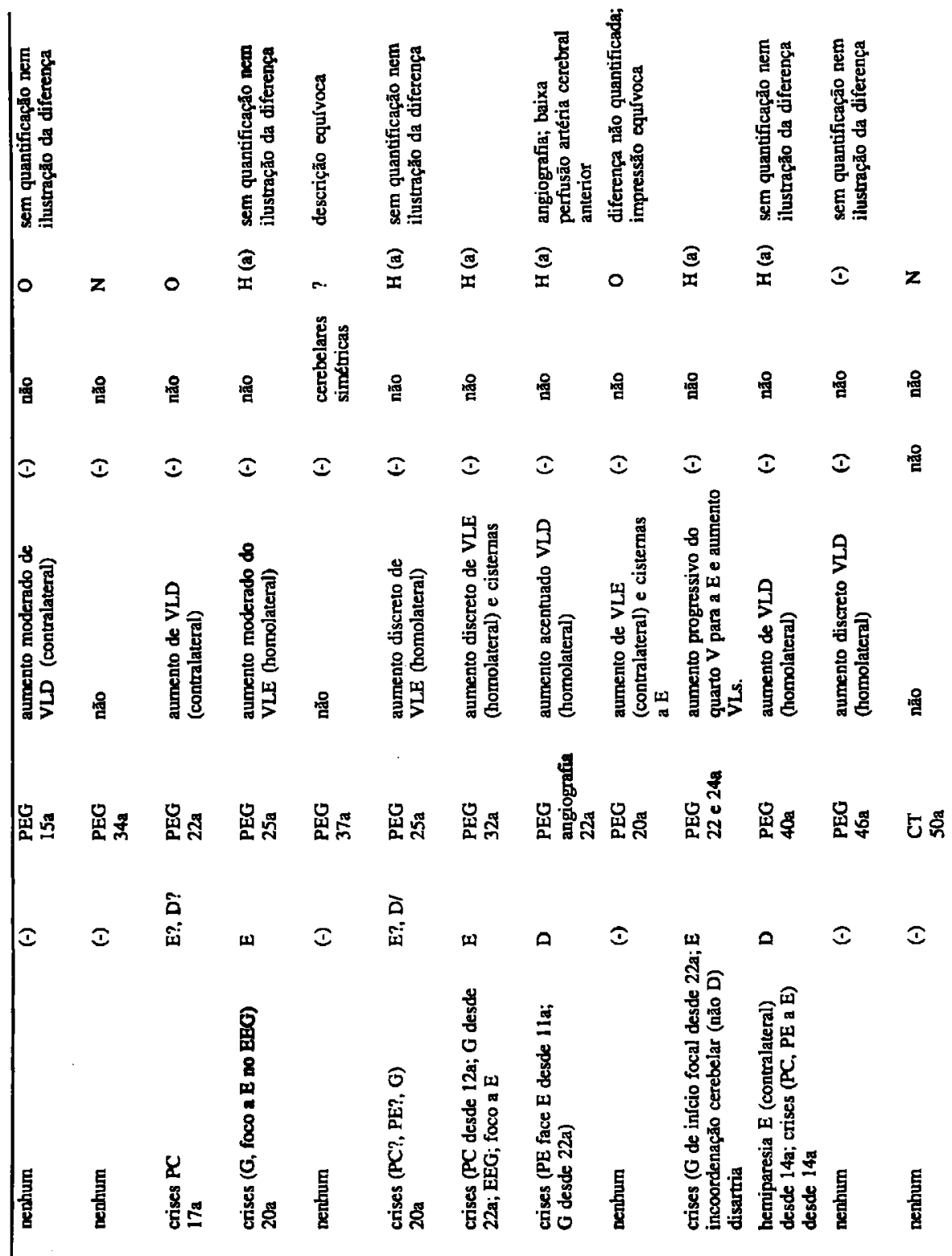

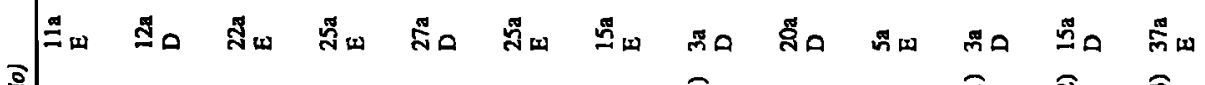
त) $\bar{a}$ a

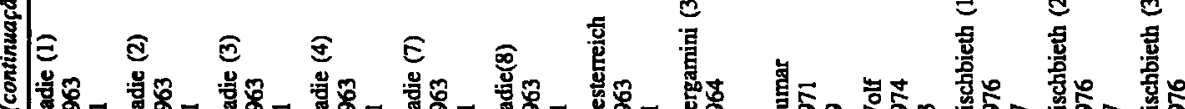



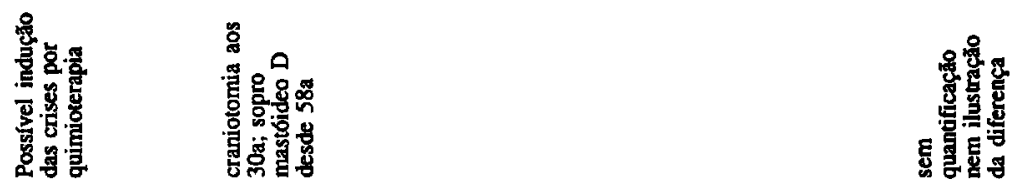

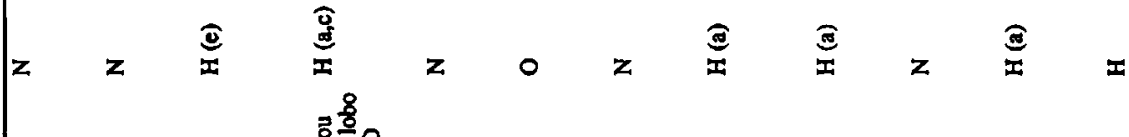

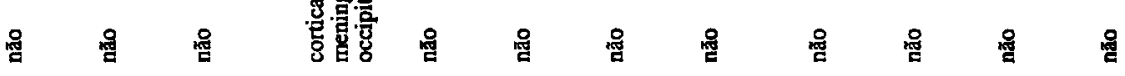
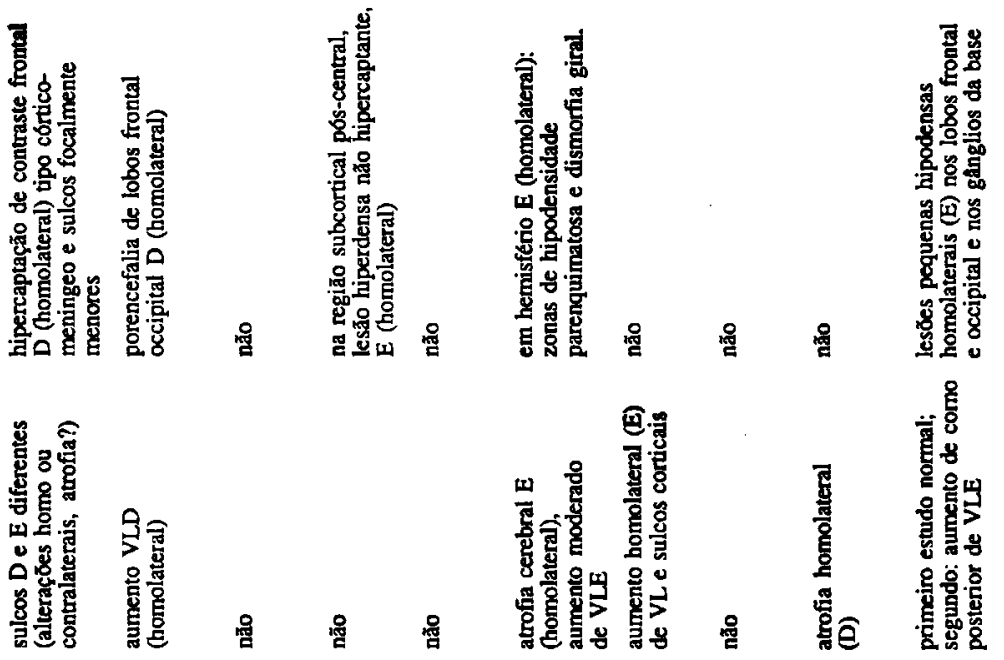

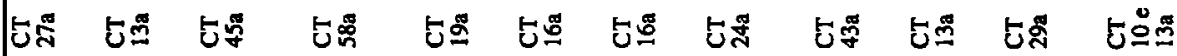
م.

ミ

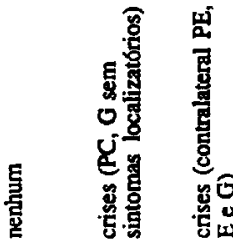
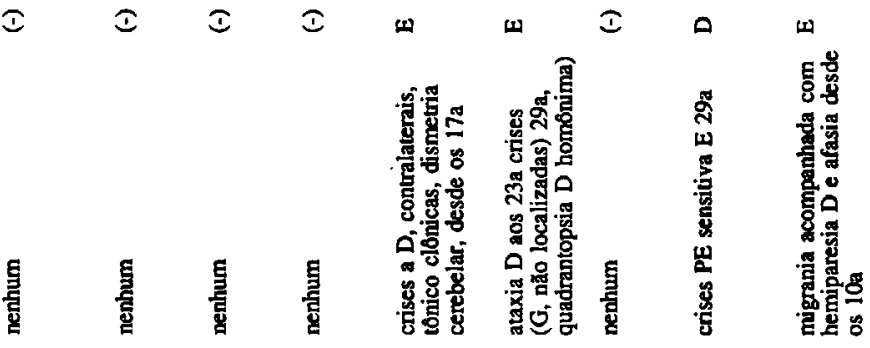

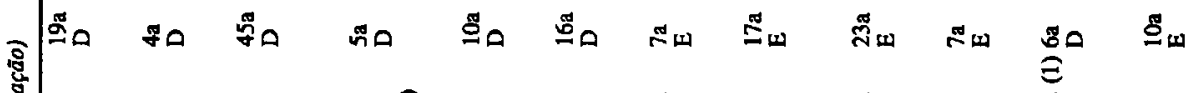

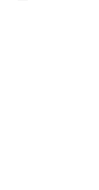




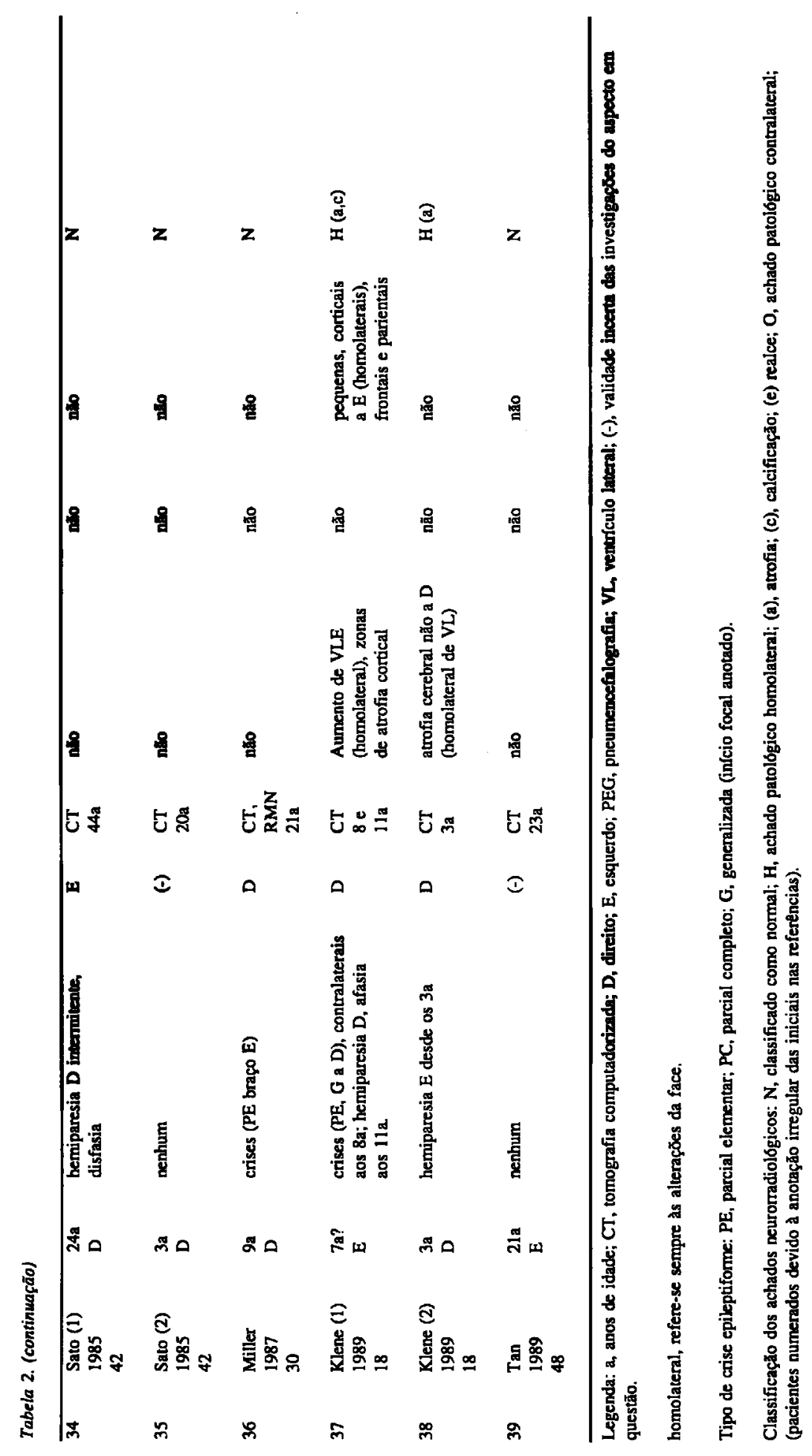


A aracnóide estava opaca, fibrótica, espessada e parecia aderente à superfície cerebral hemisférica. Os sulcos corticais eram amplos e preenchidos com camadas de pia espessadas e os giros corticais estavam atróficos, especialmente na convexidade do lobo frontal homolateral. Não foi realizado exame histologico. $O$ paciente examinado por Stief exibia assimetria hemisférica grosseira, histologicamente caracterizada por alterązes microvasculares disseminadas severas em todo hemisfério homolateral ${ }^{45}$, descritas como estase vascular. Este paciente tinha aderências meníngeas $e$ as leptomeninges foram descritas como opacas $e$ espessadas, mas não foi notada qualquer lateralizaçăo. Wartenberg, Jakob e Fünfgeld ${ }^{52}$ examinaram material da biópsia cerebral de um paciente com HFP e epilepsia Jacksoniana contralateral iniciada do lado direito aos 10 anos e, depois, epilepsia Jacksoniana esquerda iniciada aos 18 anos; a biopsia foi feita aos 19 anos. A histologia revelou meningoencefalite subaguda. Os autores descreveram proliferaçāo fibrosa pial com infiltração linfocftica. Na camada externa da substância cinzenta e também na substância branca havia infiltraçăo linfocitica maciça com predominância nas regiōes perivasculares. Alén disso existia proliferação glial extensa, sugerindo certa cronicidade. Wolf e Verity ${ }^{53}$ fizeram biópsia cerebral e cerebelar num paciente com 25 anos e que tinha HFP do lado esquerdo desde os 5 anos e "sintomas centrais" desde os 22 anos. Os achados cerebelares incluiam leve gliose, alteraçð̌es degenerativas e vacuolares e fibrose leptomenf́ngea. As leptomeninges apresentavam vasos atípicos, tortuosos com hialinizaçăo das paredes, os quais foram interpretados como malformação vascular microscópica. Nenhuma reação inflamatória foi notada.

\section{COMENTÁRIOS}

Os diferentes modelos patogenéticos apresentados para explicar a HFP podem ser grosseiramente divididos em dois grupos. Um grupo é baseado na suposiçăo de que a "trofoneurose", isto $\epsilon$, a disfunçăo de nervos tróficos, leve a atrofia facial. Ele foi introduzido por Romberg ${ }^{39,40}$. Este grupo se divide em submodelos que competem entre si, ora atribuindo o papel principal ao quinto nervo ${ }^{39,40}$ ou enfatizando a influência de fibras simpáticas cervicais e faciais ${ }^{2}$, ora atribuindo a disfunção trófica às lesōes adquiridas, localizadas em centros hipotalâmicos do $\mathrm{SNC}^{\mathrm{x} \text {, }}$, ou mesmo a uma etiologia heredodegenerativa a nível desconhecido, possivelmente hipotalâmico ${ }^{51}$. Tem-se a impressăo de que esta progressiva centripetalizaçăo da lesão advenha da dificuldade de explicar a manifestação do acometimento do SNC somente pela disfunção de nervos autonômicos periféricos. Os achados de autopsia, de uma neurovasculite facial proliferativa ${ }^{2527}$, foram explicados como resultantes da disfunção neurotrófica, porem este fato tem sido, surpreendentemente, pouco discutido.

Um grupo de modelos, que tem merecido pouca atençăo, foi primeiramente proposto por Lande ${ }^{2122}$ e se baseou na pressuposição de uma moléstia primária do tecido conjuntivo da face. Foi denominada "aplasia laminar" e nos referiremos a ela como "doença do tecido" daqui para a frente. Supunha-se que alteraçðes do tecido acometido causassem distúrbio mais ou menos mecânico dos nervos que as cruzassem, o que explicaria os irregulares sintomas de nervos cranianos. Möbius apresentou forte argumento apoiando sua propria concepçăo de doença do tecido, hipotetizando o envolvimento de agente infeccioso desconhecido, sugerido pela alta incidência de infecçŏes bucais prévias nos 100 casos relatados àquela época ${ }^{30}$. Recentemente Abele ${ }^{1}$, que pode ser considerado um sucessor desta escola, baseando-se em uma única observação propós que bactérias das espécies das borrelias desempenhassem papel na etiologia de pelo menos uma parte das HFP.

Os sintomas de nervos cranianos e de nervos simpáticos cervicais e faciais na HFP incluem frequentes disfunçðes pupilares de vários tipos. $O$ acometimento de porçōes motoras e sensitivas do quinto nervo, paresia facial e do terceiro nervo podem existir em combinaçס̄es variadas e irregulares ${ }^{2,51}$. Tais sintomas de nervos periféricos podem ser facilmente explicados tanto pelos modelos de trofoneurose como do de doença do tecido. Além do mais, nas formas em que se suspeitava de acometimento de SNC em pacientes com episódios de cefaleia ou meningite ao início da doença, em alguns casos foram relatados sintomas inequívocos de acometimento do SNC, como epilepsia por exemplo. Tais "sintomas centrais" sāo difíceis de ser explicados pelos modelos de trofoneurose trigeminais ou simpáticos, pois é costumeiramente aceito que a vascularização e a nutriçăo do cérebro sejam independentes de influências neurotróficas. As teorias da "trofoneurose central" segundo as quais uma lesăo no sistema autonômico em nível superior ${ }^{25.26}$ pode explicar o "envolvimento central", são apenas um pouco mais convincentes. Entretanto, o modelo de "doença do tecido" exige a propagaçäo de um processo inflamatório ou outro tipo de degeneração multissistêmica através de diferentes estruturas, inclusive ossos, nos pacientes com acometimento cerebral. Nenhum agente ou reação autoinflamatória primária localizada, capaz de tal invasāo transcraniana, foi identificado, até o presente. Porém, certamente tais agentes ou reaçōes nāo deveriam ser excluídos da discussäo. A incidência de "sintomas centrais" na HFP não parece ter sido avaliada, mas tem sido repetidamente citada desde que Beer publicou sua revisão em 18984 . Ele aceitou epilepsia, 
vertigem ou doença psiquiátrica para a inclusão e estabeleceu uma taxa de 15\%. A julgar pelo processo de seleçăo da revisão, deveríamos "grosso modo" considerar uma taxa certamente menor que $10 \%$, baseada em nosso próprio critério "acometimento central".

Investigamos a patologia cerebral na doença de Romberg considerando que o tipo de acometimento central possivelmente levaria a melhor compreensão da síndrome. Desta forma realizamos RMN em três pacientes com HFP. Somente um deles, HU, tinha sintomas neurológicos acometimento central, atribuído ao hemisfério esquerdo homolateral ao processo da face. A RMN nos dois pacientes sem sinais centrais mostraram-se completamente normais. A RMN do paciente HU revelou as alteraçōes complexas já descritas, ou seja, dismorfia giral homolateral com alteraçōes córtico-meníngeas, aumento monoventricular homolateral $\mathbf{e}$ alteraçðes da substância branca, grosseiramente correspondendo anatomicamente às alteraçð̄es cutâneas extracranianas e, ao mesmo tempo, ao território da artéria cerebral anterior. Espessamento e aumento em placas foram mostrados em ramos das artérias cerebrais média e anterior. Tais achados não parecem ser satisfatoriamente explicados pelos modelos trofoneuróticos de patogênese. Esta nossa impressão é devida principalmente a fatores como a dismorfia córtico- meníngea, que nāo se assemelha à de outras hemiatrofias cerebrais, como por exemplo na da síndrome de Dyke-Davidoff-Masson de origem vascular ${ }^{10.43 .54}$. Isto nos levou a rever criticamente os exames patológicos e neurorradiológicos do envolvimento cerebral nos estudos mais antigos. É nossa hipótese que o acometimento cerebral típico da sindrome de Romberg se assemelhe aos achados de nosso paciente, ou seja, homolateral, não presente em todos casos de HFP. Um outro objetivo foi identificar possíveis semelhanças com as complexas alteraçס̄es acima descritas que parecem incompatíveis com um processo atrófico năo complicado. A revisão revelou descriçð̄es muito díspares nos achados neurorradiológicos dos 40 relatos de 39 pacientes. Somente um paciente (incluindo $24 \mathrm{com}$ "sintomas centrais") tinha "déficits" atribuíveis ao hemisfério cerebral contralateral ao acometimento facial. Isto nitidamente apoia a expectativa de que a lesão deva estar localizada principalmente no hemisfério homolateral. Entretanto, os dados clínicos naturalmente não exluem a possibilidade de que o envolvimento possa ser bilateral, mais extenso ipsilateralmente.

Alguns pacientes com HFP foram descritos como apresentando achados normais. A correlaçăo entre achados normais à PEG e à CT e a ausência de sintomas centrais parece alta, ainda que năo se tenham efetuado cálculos estatísticos que provassem tal correlação. A ausência de achados cerebrais em pacientes com HFP e sem sintomas centrais năo é surpreendente. Poucos autores propuseram que lesões centrais, principalmente diencefálicas (hipotalâmicas), poderiam ser responsáveis pelas alteraçōes tróficas da face ${ }^{\mathbf{3} 20.51}$. Contudo, alguns dos pacientes revisados que tinham epilepsia ou "deficits" neurológicos focais altamente indicativos de acometimento central também tinham achados neurorradiológicos normais ( 5 casos). Tal fato pode ser atribuído à baixa sensibilidade dos métodos empregados. No entanto, se os exames incluíssem três CT, uma das quais complementada por estudo adicional pela RMN, é possivel concluir que qualquer acometimento cerebral na HFP pode ser sutil, indetectável, mesmo com técnicas aprimoradas.

O achado neurorradiológico mais frequente foi atrofia cerebral ou, em raros casos, cerebelar homolateral à atrofia da face. A concordância entre o lado do achado neurorradiológico e o da sintomatologia clínica foi alta. Tais achados neurorradiológicos indicam que o hemisfério contralateral parece estar praticamente preservado na maioria dos pacientes. Outros achados homolaterais foram calcificaçð̄es (em três pacientes), realce (cortical ou meníngeo), hipodensidade cerebral e alteraçōes arteriais, cada alteração em um paciente.

Poucos autores apresentaram casos de achados contralaterais (quatro pacientes) que consistiam em aumento ventricular (três pacientes) e lesāo parenquimatosa (um paciente). Em dois destes casos, os aumentos ventriculares não foram quantificados (Tabela 2: 10,18). Três desses pacientes não tinham qualquer sintomatologia neurológica, diferindo sobremaneira do grupo de pacientes com achados neurorradiológicos homolaterais. Podese então indagar se haveria alguma ligação entre os achados neurorradiológicos contralaterais e a HFP. Um dentre os quatro pacientes tinha "sintomas centrais" (Tabela 2: 12). A ilustração da PEG deste paciente mostra ventrículo lateral contralateral nitidamente aumentado. Por outro lado, deve-se notar que nem os sintomas $e$ nem o EEG permitiram confirmar o envolvimento do hemisfério contralateral. Assim, à luz dessas consideraçöes críticas dos achados revistos, o acometimento contralateral à HFP nos três pacientes parece ser questionável. Mas a evidencia, oriunda de um único relato, năo permite a exclusão completa da possibilidade. A grande preponderância de acometimento hemisférico homolateral na HFP claramente exclui que a ocorrência seja pura coincidência, embora a patogênese permaneça obscura.

Numa análise crítica, algumas das CTs publicadas por diversos autores parecem se assemelhar aos achados de RMN (ventriculo lateral grande, sulcos desproporcionalmente pequenos e dismorfia meningo-cortical) 
do nosso paciente HU. Hipodensidade de parênquima cerebral à CT, presumivelmente relacionada às imagens hiperintensas em T-2 de nosso paciente foi explicitamente relatada em um paciente. Porén retrospectivamente é reconhecida nas CTs de outros pacientes. Para ilustrar este fato, apresentamos a CT de DAM (Fig 2), caso previamente relatado por um de nos (JGS), para demonstrar a semelhança dos achados ${ }^{45}$. Pela nossa revisão, concluimos que o padrão típico de acometimento do SNC na HFP é a atrofia do cérebro ou cerebelo homolateral, caracterizada por aumento ventricular. A desproporção ventrículo-sulcal, a dismorfia córtico-meníngea e as alteraçð̄es de substância branca, mostradas claramente na RMN do paciente HU, são reconhecíveis retrospectivamente (porém menos distintamente) em alguns casos previamente relatados. Por serem tais aspectos certamente um achado incomum, quando comparado a formas de hemiatrofias vasculares ${ }^{43.54}$ ou de atrofias cerebrais bilaterais comuns, suspeitamos que sejam tais aspectos relacionados a um processo atípico, nāo primariamente trófico, que leve a atrofia secundária.

Os achados histológicos da HFP são inequívocos e revelam neurovasculite intersticial proliferativaa.7.4. Um dos três relatos de autópsia revistos não menciona patologia cerebral ou cerebelar, num paciente sem sintomatologia indicativa de envolvimento central ${ }^{27}$. Nossos dois pacientes (HS e ML) tinham achados normais e parece que pertencem a esse grupo. Tais achados normais a RMN, nesses dois pacientes, pareceriam provar que alguns casos de HFP não têm nem mesmo discretas lesões. Contudo, diferenças grosseiras entre os hemisférios cerebrais em pacientes com HFP e com "sintomas centrais" foram encontradas em autópsias em pelo menos duas vezes, em concordância com os achados neurorradiológicos que demonstram patologia mono-hemisférica. Uma destas autopsias descreve acentuada atrofia cortical homololateral e dismorfia giral, com espessamento meníngeo e aderências. $O$ outro paciente tinha assimetria hemisférica grosseira, espessamento meníngeo e aderências. As biópsias dos dois pacientes revelaram, no primeiro meningoencefalite subaguda, com infiltrados linfocíticos corticais e subcorticais e acentuada proliferaçāo meníngeas". No segundo, fibrose leptomeníngea, com alguns vasos atípicos tortuosos e hialinizados, gliose subcortical; nāo foram encontradas alteraçőes inflamatórias ${ }^{53}$. Evidentemente, ambas biópsias e ambas as autópsias descrevem alteraçðes meningo-corticais homolaterias à atrofia facial. Todos os relatos também mencionam alteraçóes vasculares grosseiras, ou seja, equimose, estase vascular, infiltraçăo capilar e vasos de médio calibre tortuosos e parcialmente ocluídos. Estes achados patológicos raros não apoiam a suposição de uma simples atrofia cerebral nos pacientes com HFP com acometimento central. Em apenas um caso (do total de quatro) de relato de biópsia e autópsia foi proposto um diagnóstico final de meningoencefalite subaguda. Com relaçāo aos diferentes intervalos entre o início dos sintomas e a realização dos exames, é importante considerar que a estase vascular, fibrose, gliose e as alteraçðes vasculares poderiam estar presentes em diferentes estágios de um processo inflamatório subjacente. Os outros achados de biópsia ou autópsia nāo necessariamente se contrapōem a esse diagnóstico. As alteraçōes vasculares descritas na angiografia de um paciente (Tabela 2: 17) e o espessamento arterial visto em nossas RMNs poderiam indicar um papel ativo dos vasos em tal processo.

Muitos relatos que mencionaram atrofia cerebral/cerebelar neurorradiológicas não se detiveram no substrato de tal atrofia. A morfologia do acometimento central de nosso paciente HU, e comparavelmente à do paciente DAM anteriormente apresentado (Fig 2) e provavelmente à de outros, parece ser inconsistente com modelos de trofoneurose. É nossa opinião que ela suporte os conceitos básicos de Lande e Möbius e possivelmente a avaliação de Abele'. As áreas de calcificação descritas por alguns outros autores no hemisfério homolateral também não dão suporte à hipótese de uma atrofia nutritiva. As características descritas neste grupo de pacientes bem que poderiam estar relacionadas às alteraçōes meníngeas grosseiras (proliferações e/ou aderências) mencionadas em todas as autópsias e biópsias revisadas. Ainda que nāo possamos nos apoiar firmemente nos resultados das biópsias e apesar de revelar o LCR resultado normal em um paciente aos 60 anos, acreditamos que um processo inflamatório levaria à atrofia de vários tecidos da face e, às vezes, de porçð̄es adjacentes do cérebro. Propomos que os achados do paciente HU sejam consistentes com meningoencefalite crônica focal ou hemisférica com envolvimento vascular e que sejam uma complicação ocasional da síndrome de Romberg. conforme foi primeiramente sugerido por Wartenberg, Jakob e Füngfeld ${ }^{32}$. A neurovasculite proliferativa infiltrativa da face em pacientes com HFP, fator reconhecido na moléstia há mais de um século ${ }^{27,34}$,e as alteraçōes centrais ocasionais podem ser explicadas como partes de um mesmo processo inflarnatório.

\section{CONCLUSס̃ES}

1. A hemiatrofia homolateral do cérebro e/ou cerebelo vista no caso $\mathrm{HU}$ poderia parecer ocasional, porém é típica dos achados de acometimento do SNC na síndrome de Romberg, conforme provado pela revisão. Parece que o acometimento cerebral contralateral tenha, se tiver, apenas um 
papel menor. Outros aspectos vistos nesse caso, como as alteraçð̃es vasculares e de substância branca meningocortical, retrospectivamente comprovaram-se não serem achados isolados, se se considerarem as limitaçōes dos antigos métodos de investigação.

2. A ocorrência ocasional de acometimento do SNC, aparentemente não se enquadra nos modelos de trofoneurose, do ponto de vista das características morfologicas especificadas acima. Contudo, parece ser inútil dividir a síndrome de Romberg em subgrupos com e sem acometimento do SNC. Preferimos, portanto, sugerir que seja abandonado o modelo de trofoneurose para HFP como originalmente proposto por Romberg. O modelo proposto, de moléstia tecidual causada por agente inflamatório com predileçăo para tecido nervoso e vasos e que por vezes invada o crânio, pareceria altamente plausível.

3. Arriscariamo-nos propor, porém sem a evidência histológica que poderia advir de biópsias cerebrais, que o substrato patológico da atrofia hemisférica homolateral com dismorfia meningocortical se assemelha a meningoencefalite subaguda, como descrita por Wartenberg, Jakob e Füngfeld em 1925, ou a alteraçōes residuais de tal processo.

4. Como a doença em seus estadios finais pode determinar grandes mutilaçōes e devido aos achados microbiológicos recentemente apresentados por Abele e a consequente curabilidade potencial, sugerirfamos exaustivas investigaçóes microbiologicas nos tecidos de pacientes com a doença de Romberg, especialmente nos pacientes em que ela se instalou recentemente.

\section{REFERENCIAS}

1. Abele DC, Bedingfield RB, Chandler FW, Given KS. Progressive facial hemiatropy (Parry-Romberg syndrome) and borreliosis. J Am Acad Dermatol 1988, 19: 820-825.

2. Archambault LS, Formm NK. Progressive facial hemiatropy: report of three cases. Arch Neurol Psychiatr 1932, 27:529-584.

3. Asher SW, Berg BO. Progressive facial hemiatrophy: report of three cases, including one observed over 43 years, and computed tomography findings. Arch Neurol 1982, 39:44-46.

4. Beer M. Beitrag zur Kenntnis der Hemiatrophia facialis progressiva. Inaug Dissert Konigsberg i. Pr.: Krause u. Ewerlein 1898, p 38.

5. Bergamini L, Ferraris F, Inghirami L. Osservazioni clinico elettroencefalografiche in pazienti affeti da emiatrofia facciale progressiva com epilessia. Acta Neurol (Napoli) 1964, 19: 1000-1014.

6. Brain R. Diseases of the nervous system. Ed 6. London: Oxford Univ Press, 1962, p 548-552 (originally presented in Ed 2, 1940).

7. Cassirer R. Vasomorisch-Trophischen Neurosen. Berlin: Karger, 1912.

8. Chasanow M. Beiträge zur Ätiologie der Hematrophie des Gesichts. Ztschr Ges Neurol Psychiatr 1932, 140: 474-485.

9. Duro LAA, Lima JMB, Reis MM, Silva CV. Atrofia hemifacial progressiva (doença de Parry-Romberg): estudo de um caso. Arq Neuropsiquiatr 1982, 40:193-200.

10. Dyke CG, Davidoff LM, Masson CB. Cerebral hemiatrophy with homolateral hypertropy of the skull and sinuses. Surg Gynecol Obstetr 1933, 57: 588-600.

11. Eadie MJ, Sutherland JM, Tyrer JH. The clinical features of hemifacial atrophy. Med J Aust 1963, 50:177-80.

12. Fromhold-Treu A. Die Hemiatrophia facialis progressiva. Inaug Dissert. Dorpat (Jurjew): Schnakenburg's Buchdruckerei 1893, p 78-84.

13. Graff $H$. Hemiatrophia facialis progressiva verbunden mit neuroparalytischer Ophtalmie. Inaug Dissert. Dorpat (Jurjew): Laakmann, 1886, p 10-15.

14. Homen EA. Zur Kenntris der Hemiatrophia facialis und des Ursprungs des Nervus trigeminus. Neurolog Centralbl $1890,9: 385-388 \& 430-438$.

15. Jolly F. Ueber multiple Hirnsklerose. Arch f Psychiatr Nervenkrankh 1872, 3: 711-730.

16. Jurkiewicz MJ, Nahai $F$. The use of free revascularized grafts in the amelioration of hemifacial atrophy. Plast Reconstr Surg 1985, 76: 44-54.

17. Kaufman MD. Masticatory spasm in facial hemiatrophy. Ann Neurol 1980, 7: 585-587.

18. Klene C, Massicot P, Ferriere-Fontane I, Sarlangue J, Fontan D, Guillard JM. Sclerodermie en coup de sabre et . hemi-atrophie faciale de Parry-Romberg. Ann Pediatr 1989, 36: 123-125.

19. Kumar F, Agrawal BV, Singh NP, Mukerji M, Edoliya TN. Progressive right hemifacial atrophy with contralateral cerebral hemiatrophy. J Assoc Physicians India 1971, 19: 595-597.

20. Lakhani PK, David TJ. Progressive hemifacial atrophy with scleroderma and ipsilateral limb wasting (ParryRomberg syndrome). J R Soc Med 1984, 77: 138-139.

21. Lande L. Essai sur l'aplasie lamineuse progressive. These No 278. Paris, 1869. 
22. Lande L. Sur une forme d'atrophie partielle de la face. Arch Gen Med 1870, 15: 315-332.

23. Lederman R. Progressive facial and cerebral hemiatrophy. Clev Clin Q 1982, 51:545-548.

24. Lewkonia RM, Lowry RB. Progressive hemifacial atrophy (Parry-Romberg syndrome) report with review of genetics and nosology. Am J Med Genet 1983, 14: 385-390.

25. Loebl H, Wiesel J. Zur Klinik und Anatomie der Hemiatrophia facialis progressiva. Dts Ztschr Nervenheilk 1904, 27: 355-372.

26. Mankowski BN. Zur Pathogenese der Hemiatrophia facialis (Ein Fall von symptomatischer Herniatrophie nach Enzephalitis epidernica). Arch Psychiatr 1928, 78:572-580.

27. Mendel E. Zur Lehre von der Hemiatrophia facialis. Neurolog Centralbl 1888, 7: 401-414.

28. Merrit KK, Faber HK, Bruch H. Progressive facial hemiatropy: report of two cases with cerebral calcifications. J Pediatr 1937, 10: 374-395.

29. Miller MT, Sloane H, Goldberg MF, Grisolano J, Frenkel M, Mafee M. Progressive hemifacial atrophy. J Pediatr Ophtalmol Strabismmus 1987, 24: 27-36.

30. Mobbius PJ. Der umschiriebene Gesichtsschwund. In Nothnagel CWH (ed). Specielle Pathologie und Teraphie, Vol 2, Part 2. Vienna: Hölder, 1895.

31. Oesterreich K. Zur Frage der Pathogenese der Hemiatrophia faciei. Nervenarzt 1963, 34:262-265.

32. Paradise JE, Raney B, Whitaker LA. Progressive facial hemiatrophy: report of a case associated with Ewings sarcoma. Am J Dis Child 1980, 134: 1065-1067.

33. Parry CH. Collections from the unpublished medical writings of the late Caleb Hilier Parry. London: Underwoods $1825, \mathrm{p}$ 478-480.

34. Pensler JM, Murphy GF, Mulliken JB. Clinical and ultrastructural studies of Romberg's hemifacial atrophy. Plast Reconstr Surg 1990, 85: 669-674.

35. Poch GF, Cordero AA. Algunos conceptos sobre la etiopatogenia de la hemiatrofia facial. Prensa Med Arg 1956, 43: 2945-2949.

36. Rees TD. Facial atrophy. Clin Plast Surg 1976, 3: 637-646.

37. Rischbieth RHC. Progressive facial hemiatrophy (Parry-Romberg syndrome). Proc Aust Assoc Neurol 1976, 13: 109-112.

38. Rogers BO. Progressive facial hemiatrophy: Romberg's syndrome. A review of $\mathbf{7 7 2}$ cases. In: Transactions of the third international congress of plastic surgery. Internat Congr Series No 66. Washington: Excerpta Medica Foundation, 1963, p 681-689.

39. Romberg MH. Klinische Ergebnisse. Berlin A: Forstner, 1846, p 75-81.

40. Romberg MH. (ed). Klinische Wahrnehmungen. Berlin: Wilhem Hertz, 1851, p 83-93.

41. Sagild JC, Alving J. Hemiplegic migraine and progressive hemifacial atrophy. Ann Neurol 1985, 17:620.

42. Sato T, Lima LA, Oliviera MKF. Hemiatrofia facial progressiva: atualização. Neurobiologia (Recife) 1985 , 48: 217-226.

43. Sener RN, Jinkins JR. MR of craniocerebral hemiatrophy. Clin Imaging 1992, 16: 93-97.

44. Shanker A, Datye MD, Gagrani SP. Facial hemiatrophy with hemiatrophy of the brain. J Indian Med 1963, 40: 467-469.

45. Speciali JG, Resende LAL. Hemiatrofia facial progressiva: registro de um caso. Arq Neuropsiquiatr 1984, 42 : $166-170$.

46. Stief A. Über eine Fall von Hemiatrophie des Gesichtes mit Sektionsbefund. Zbl Neurol 1925, 45: 574-593.

47. Stiefler G. Über die Hemiatrophia faciei progressiva bilateralis. Jahrb Psychiatr Neurol 1934, 51: 278-292.

48. Tan E, Kurkçüoglu N, Atalag M, Gökoz A, Zileli T. Progressive hemifacial atrophy with localized scleroderma. Eur Neurol 1989, 29: 15-17.

49. Touche M. Deux cas d'hemiatrophie faciale avec autopsie. Rev Neurol 1902, 10: 375-376.

50. Tuffanelli DL, Marmelzat WL, Dorsey CS. Linear scleroderma with hemiatrophy. Dermatologica 1966, 132: $51-58$.

51. Wartenberg R. Progressive facial hemiatrophy. Arch Neurol Psychiatr 1945, 54: 75-96.

52. Wartenberg R, Jacob R, Füngfeld A. Zur Klinik und Pathogenese der Hemiatrophia faciei progressiva. Arch $f$ Psychiatr 1925, 74: 602-630.

53. Wolf SM, Verity MA. Neurological complications of progressive facial hemiatrophy. J Neurol Neurosurg Psychiatry 1974, 37: 997-1004.

54. Zeiss J, Brinker RA. MR imaging of cerebral hemiatrophy. JCAT 1988, 12: 640-643. 